\title{
Automatic affective-motivational regulation processes underlying supportive dyadic coping: the role of increased implicit positive attitudes toward communal goals in response to a stressed relationship partner
}

Nicolas Koranyi, Peter Hilpert, Veronika Job \& Guy Bodenmann

To cite this article: Nicolas Koranyi, Peter Hilpert, Veronika Job \& Guy Bodenmann (2017): Automatic affective-motivational regulation processes underlying supportive dyadic coping: the role of increased implicit positive attitudes toward communal goals in response to a stressed relationship partner, Anxiety, Stress, \& Coping, DOI: 10.1080/10615806.2017.1292421

To link to this article: http://dx.doi.org/10.1080/10615806.2017.1292421

曲 Published online: 20 Feb 2017.

Submit your article to this journal ¿

View related articles

View Crossmark data $\nearrow$ 


\title{
Automatic affective-motivational regulation processes underlying supportive dyadic coping: the role of increased implicit positive attitudes toward communal goals in response to a stressed relationship partner
}

\author{
Nicolas Koranyi ${ }^{a}$, Peter Hilpert ${ }^{b}$, Veronika Job ${ }^{c}$ and Guy Bodenmann ${ }^{c}$ \\ ${ }^{a}$ Department of Psychology, Friedrich Schiller University Jena, Jena, Germany; ${ }^{b}$ Department of Psychiatry and \\ Behavioral Sciences, University of Washington, Seattle, WA, USA; 'Department of Psychology, University of Zurich, \\ Zurich, Switzerland
}

\begin{abstract}
Background and objectives: We examined the implicit affective mechanisms underlying provision of support in intimate dyads. Specifically, we hypothesized that in individuals with high relationship satisfaction, the perception that one's partner is stressed leads to increased implicit positive attitudes toward communal goals. In turn, this change in implicit attitudes facilitates supportive behavior.

Design and methods: In two studies, we induced partner stress by instructing participants to either recall a situation where their partner was highly stressed (Study $1 ; N=47$ university students) or imagine a specific stressful event (excessive workload; Study 2; $N=85$ university students). Subsequently, implicit attitudes toward communal goals were assessed with an Implicit Association Test.

Results: In both studies, we found that among participants with high relationship satisfaction partner stress increases preferences for communal goals. In addition, implicit preferences for communal goals predicted stronger inclinations to engage in supportive dyadic coping (Study 2).

Conclusions: The current findings provide important insights into the implicit cognitive-affective mechanics of dyadic coping. Moreover, they can explain how people manage to avoid experiencing motivational conflicts between partner-oriented and self-oriented goals in situations characterized by high partner stress.
\end{abstract}

\section{ARTICLE HISTORY}

Received 6 April 2016

Revised 1 December 2016

Accepted 8 December 2016

\section{KEYWORDS}

Intimate relationships; selfregulation; dyadic coping; social support; communal goals

\section{Introduction}

Harry had a bad day at work: His supervisor criticized him in front of the whole team because the projects Harry is responsible for are not progressing as planned. Severely stressed and emotionally upset he comes home. When entering the house, his wife Sally is still working on her latest book project. However, when she sees Harry being stressed and emotionally down, she immediately interrupts her work, turns to Harry, and offers him empathetically to talk about his day. She shows interest and understanding. In the end, she offers to cancel the planned joint weekend trip to her parents in order to give him more time to get his projects back on track.

What are the motivational processes underlying Sally's empathetic responding? In the present research, we aim at contributing to this question by suggesting a new perspective on coping 
behavior in couples. Specifically, we propose that in high-functioning couples, the provision of support is facilitated by an implicit process according to which the perception that one's partner is emotionally upset and stressed leads to increased implicit positive attitudes toward communal, helping-related goals, which in turn facilitates provision of support.

\section{Dyadic coping}

It is a core characteristic of high-functioning intimate relationships that partners usually provide support when they perceive that the other partner is stressed or emotionally upset. ${ }^{1}$ In fact, for adults, the relationship partner is of primary significance in times of need and typically far more important than other potential sources of social support (e.g., friends or relatives; Bodenmann, 1995, 2005; Coyne \& DeLongis, 1986; Revenson, 1994). To acknowledge the couple's unique role in dealing with everyday hassles and disturbances, Bodenmann $(1995,2005)$ introduced the concept of dyadic coping, which subsumes various forms of how couples cope with stress together. Among different forms of dyadic coping (joint dyadic coping, delegated dyadic coping, negative dyadic coping), supportive dyadic coping describes problem- or emotion-focused support provided by one partner in an attempt to assist the other partner in his/her coping efforts (Bodenmann, 2005).

Supportive dyadic coping in intimate relationships is especially relevant when one partner is confronted with relationship external stress (e.g., work load and social stress with neighbors or kin). It comprises, for instance, offering empathic understanding, helping the partner to reframe the situation, communicating a belief in the partner's capabilities, or providing practical and helpful advice (Bodenmann, 2005). Numerous correlational and longitudinal studies have shown that dyadic coping in couples is associated with higher marital quality (see meta-analysis by Bodenmann, Pihet, \& Kayser, 2006; Falconier, Jackson, Hilpert, \& Bodenmann, 2015; Herzberg, 2013; Papp \& Witt, 2010), and better psychological and physical well-being (e.g., Badr, Carmack, Kashy, Cristofanilli, \& Revenson, 2010; Bodenmann, Meuwly, \& Kayser, 2011). The significant and consistent relationship between dyadic coping and relationship functioning has been reported in 14 different cultures (Falconier, Randall, \& Bodenmann, 2016).

Importantly, research suggests that there is a reciprocal relationship between dyadic coping and relationship satisfaction. Findings from longitudinal studies show that relationship quality and (explicitly reported) dyadic coping are related to each other over time (e.g., Bodenmann et al., 2006; lida, Seidman, Shrout, Fujita, \& Bolger, 2008). Hence, partners who are highly satisfied in their relationship are the most willing to support their stressed partners, which in turn fosters relationship quality. On the other hand, if partners are not satisfied in their relationship they are less likely to engage in dyadic coping potentially resulting in even lower relationship quality over time. In the Systemic Transactional Model (STM; Bodenmann, 1995, 2005), these processes are described in more detail. One aspect (among others) that receives special attention in STM are goals or motivational aspects related to commitment, relationship satisfaction, and personality traits to engage in dyadic coping, either supportive or common/joint dyadic coping. Although postulated in the model, motivational processes underlying dyadic coping and provision of support in intimate relationships have not been empirically studied. Thus many questions remain unanswered so far.

\section{Underlying motivations: the role of implicit self-regulation}

Why are partners who are satisfied in their relationship more likely to support their partner? What cognitive and emotional processes make them engage in dyadic coping, whereas others (those with low relationship satisfaction) tend to be less supporting and potentially withdraw from their partner when he/she is stressed? From a motivational point of view, situations in which the partner needs support bear the risk to create motivational conflicts between helping motivation (partner-oriented motives) and autonomy motives (self-oriented motives) because helping often implies having less time for one's own goals (e.g., finishing one's work or spending free time). 
Findings suggest that individuals manage to solve this conflict by recruiting counteracting cognitions or beliefs about their partner. For instance, Murray et al. (2009) found that whenever individuals have to be responsive to their partners' needs while simultaneously frustrating their own goals, they increase positive evaluations of their partner. In turn, an increased partner value strengthens commitment to one's partner and counteracts avoidance tendencies that might be activated in situations with high levels of partner stress (Murray et al., 2009).

Further research suggests that partners may base their support on principals of reciprocity. Individuals find it much easier to accommodate to their partner's needs when they feel sure about their partner's continuing positive regard (Derrick, Leonard, \& Homish, 2012; Kelley \& Thibaut, 1978; Murray, Bellavia, Rose, \& Griffin, 2003; Murray, Holmes, \& Collins, 2006), indicating that individuals provide support when they trust in their partner's future responsiveness and getting back support in times of need. These findings suggest that individuals with high relationship satisfaction manage to provide supportive dyadic coping by recruiting positive, counteracting cognitions about their partner that help to resolve potential behavioral conflicts (e.g., "he/she is so valuable" or "he/she provides also support when I'm stressed").

In addition to an intentional focus on positive partner-related cognitions, there is some evidence speaking to the role of emotion-driven processes in triggering helping behavior. For example, caregivers who are satisfied with their relationship tend to experience helping itself as positive (e.g., "I truly enjoy helping my partner"; Feeney \& Collins, 2003). Thus, besides (or instead of the activation of any intentional conflict-resolving cognitive process, individuals who are overall satisfied with their relationship engage in support behavior because they feel internally motivated to do so.

In the present research, we aimed at further examining the principals of internally motivated helping behavior in couples who are highly satisfied with their relationship. We tested the assumption that what contributes to responsive and internally motivated support behavior in highly satisfied individuals is the automatic activation of a motivational orientation toward communal, helpingrelated goals. Concretely, we hypothesize that the perception of one's stressed partner triggers an increase in implicit positive attitudes toward communal goals, which in turn facilitates supportive behaviors. Communal goals are addressed in STM (Bodenmann, 1995) in that partners perceive the stress of one member of the couple as the problem of both (interdependence) and thus supportive or joint dyadic coping emerge as a function of this perception of we-stress and communal goals. Furthermore, our hypothesis is rooted in the framework of implicit self-regulation. According to this approach, individuals who feel highly committed toward a certain goal automatically adjust cognitive and affective-motivational processes whenever goal pursuit is threatened by situational demands or challenges (e.g., Fishbach, Zhang, \& Trope, 2010; Koranyi, 2012; Koranyi, Gast, \& Rothermund, 2013; Koranyi \& Meissner, 2015; Koranyi \& Rothermund, 2012a, 2012b, 2012c; Maner, Gailliot, \& Miller, 2009; Myrseth, Fishbach, \& Trope, 2009; Shah, Friedman, \& Kruglanski, 2002). As interpersonal research has shown, in many cases automatic self-regulation involves spontaneous shifts in implicit attitudes. For example, when individuals, who are highly motivated to find a relationship partner, realize that an attractive potential mate is unavailable, they inhibit the formation of positive attitudes toward that person in order not to suffer from distressing and aversive rumination about the blocked and frustrated goal (Koranyi et al., 2013; see also O'Hagen, Johnson, Lardi, \& Keenan, 2003). Similarly, in situations where individuals have strong motivations to increase closeness to a potential partner, they neutralize negative attitudes toward dependence in order to tolerate more easily autonomy costs of an interdependent life (Koranyi \& Meissner, 2015).

In case of already established relationships, it seems likely that highly committed individuals aim at maintaining the status quo. This implies that whenever the status quo is threatened by a stressed relationship partner, these individuals should be motivated to help restoring their partner's wellbeing by engaging in dyadic coping. As STM assumes, supporting the partner in times of stress brings benefits to both partners (the support receiver and the support provider) as the attained homeostasis is beneficial for both partners' satisfaction and well-being. Dyadic coping leads, however, not only to restored stress homeostasis but also goes along with higher relationship 
functioning (higher intimacy, trust, and we-ness). Within this process, the automatic self-regulation account would predict increased positive attitudes toward communal, helping-related goals. Thereby, the emergence of any motivational conflict between helping (partner-oriented) and pursuing own goals (self-oriented) would be prevented by rendering supportive behaviors congruent with the helping partner's motivational orientation while at the same time other more personal, idiosyncratic goals (e.g., finishing one's own work) lose temporarily priority.

\section{Current studies}

In the following, we present two studies that tested whether implicit attitudes toward communal goals increase in response to a stressed relationship partner in participants with high levels of relationship satisfaction. We further aimed to examine whether increased implicit positive attitudes toward communal goals indeed predict the inclination to provide dyadic support (Study 2). In both studies, we induced partner stress with a mind-set priming. Participants were instructed to elaborate on a situation in which their partner was affected by a stressful and emotionally disturbing experience. Implicit attitudes toward communal goals were assessed with an Implicit Association Task (IAT; Greenwald, McGhee, \& Schwartz, 1998).

In correlational Study 1, we used a pre-post design in which the IAT was administered prior to and after the mind-set priming. We predicted that relationship satisfaction would be related to stressinduced increase in implicit preference for communal goals. In Study 2, we used an experimental control group design to test the assumption that the proposed process is a couple-specific reaction to a situation in which one's partner (rather than someone else) is stressed. Therefore, we compared the partner stress condition with a control group (stressed fellow student). Furthermore, we assessed behavioral inclinations to provide support in the stress-inducing situation. We expected increased implicit positive attitudes toward communal goals in the partner stress condition (vs. control group) and that this effect is especially pronounced for participants with high relationship satisfaction. Furthermore, we expected that the degree of preferences for communal goals would predict inclinations to provide supportive dyadic coping.

The studies were conducted in accordance with the principles of the Declaration of Helsinki. Informed consent was obtained from participants at the beginning of the studies.

\section{Study 1}

\section{Method}

\section{Participants}

Forty-seven students (44 female) from a German university with an average age of 20.2 years (SD= 2.5) participated in our study in exchange for partial course credit. All participants were engaged in an intimate relationship (average duration 47.6 months, $S D=97.8$ ). ${ }^{2}$

\section{Procedure and materials}

Upon arrival, participants were seated on individual computer workstations. First, participants completed a baseline assessment of implicit attitudes toward communal goals with an IAT (Greenwald et al., 1998). In the IAT, participants sort target stimuli into target categories and attribute stimuli into attribute categories, using the same two response keys for both tasks with a blockwise variation of response assignments. Differences in mean response times between blocks are typically interpreted as relative association strength between target and attribute categories and referred to as IAT effect.

The target category that represented communal goals was labeled as "warmhearted" (stimuli: warmhearted, empathetic, helpful, caring, affectionate). As contrast category we used "competent" (stimuli: competent, able, influential, skillful, clever) which represented self-oriented, agentic goals. 
We decided to use "competent" as contrast category out of two reasons: first, by using a contrast category that has also a positive valence, we aimed at lowering the influence of attitude-irrelevant processes on the IAT score (e.g., task-recoding, Meissner \& Rothermund, 2013). Second, recent findings suggest that when individuals aim at bolstering their communal orientation, they simultaneously down-regulate agentic goals (Holoien \& Fiske, 2013). For the attributes, we used the two categories "I like" (stimuli: holiday, summer, love, gift, nature, security, sun, peace, humor, paradise) and "I dislike" (stimuli: accident, war, pain, off-gas, anxiety, violence, loss, misery, noise, conflict).

Attribute stimuli were written in capital letters to simplify the distinction between the target and the attribute classification task. Following Greenwald et al. (1998), the IAT consisted of five blocks. First, participants practiced the categorization of attributes, responding to words related to "I like" with the L-key and to words related to "I dislike" with the D-key. Subsequently, participants practiced the target categorization, responding to words related to "warmhearted" with the L-key and to words related to "competent" with the D-key. This was followed by a first experimental block of combined categorizations in block 3, employing the same response assignments as in the practice tasks. In the fourth block, the target categorization was practiced with reversed response assignment, followed by another experimental block of combined categorizations using the same reversed target response assignment. We used the same block order for all participants to reduce unsystematic variability in IAT effects unrelated to our stress-inducing mind-set priming. Both experimental blocks comprised 40 attribute trials and 40 target trials, presenting all attribute stimuli twice and all target stimuli four times. Stimulus presentation order was fully randomized. In each trial, the to-be-categorized stimulus was presented and stayed on the screen until response. Wrong responses were followed by the message "Error! Continue with correct key ...", after which participants had to press the correct key to proceed. The next trial started $400 \mathrm{~ms}$ after a correct response.

After the IAT, we induced partner stress with a mind-set priming. Participants were instructed to think of a situation in which their partner was emotionally severely distressed. We explicitly stated that this situation should be relationship external (i.e., situation with absolutely no association with the partner or one's intimate relationship; see Randall \& Bodenmann, 2009), because we expect that in case of relationship-internal stress, participants would be more inclined to engage in selfdefense rather than increasing positive attitudes toward communal goals (e.g., Cavallo et al., 2010). First, participants had to provide a short description of the recalled event (events that were often listed were death or severe illness of a relative or loss of a job). Subsequently, participants had to jot down how their partner responded emotionally to the event and how these emotions influenced his/her well-being and behavior.

Directly after the partner stress induction, participants completed a post-assessment of implicit preference for communal goals with the IAT. The IAT was identical to the one we used as baseline assessment. Afterwards, participants completed a package of questionnaires. Among these questionnaires, we included the Relationship Assessment Scale (RAS; Hendrick, 1988; for the German version, see Sander \& Böcker, 1993), which measures relationship satisfaction with 7 items on 5-point Likerttype scales (example item: "In general, how satisfied are you with your relationships?"). The internal consistency of the RAS was satisfactory $(M=3.89, S D=0.69, a=.86)$.

\section{Results}

IAT effects were calculated separately for the baseline assessment and the post-assessment by subtracting mean response latencies (RTs) of the initial combined task (Block 3) from those of the reversed combined task (Block 5). ${ }^{3}$ Thus, high IAT effect scores indicate high implicit preference for communal goals. Both mean IAT effects were significantly different from zero $\left(M_{\text {baseline }}=90\right.$, $\left.S D=124, t[46]=4.99, p<.001 ; M_{\text {post }}=92, S D=88, t[46]=7.17, p<.001\right)$, indicating a tendency to prefer communal goals over agentic goals. To get a measure of partner stress-induced increase in implicit positive attitudes toward communal goals, we further subtracted the baseline IAT from the post-IAT. Higher scores indicated a stronger increase in preference for communal goals in 
response to a stressed partner. In a simple regression analysis, we regressed the IAT effect variable on a grand-mean centralized variable of relationship satisfaction. In this analysis, the intercept represents the magnitude of the pre-post effect at average values for relationship satisfaction, or in other words the main effect of measurement time. The intercept was only descriptively different from zero, $B=$ 2.38, SE $B=16.58, t(45)=0.14, p=.886, d=0.02$, which indicated that the IAT effects were not generally increased after reflecting on a stressed intimate partner. However, in line with our hypothesis, the regression analysis revealed a significant positive effect of relationship satisfaction, $B=62.57, S E B=$ $24.26, t(45)=2.58, p=.013, r=.36$. Thus, the more participants feel satisfied with their relationship, the more they showed an increase in implicit preference for communal goals after reflecting on a stressed partner. We also wanted to estimate the magnitude of the preference shift for communal goals in response to the partner stress priming for participants with high when compared with participants with low relationship satisfaction. We therefore run two additional simple regression analyses on the IAT effect variable with relationship satisfaction as a predictor. For the first analysis, relationship satisfaction was transformed such that the intercept (zero) reflects high relationship satisfaction (+1 SD). To this end, we subtracted one standard deviation from the grand-mean centered scores. For the second analysis, relationship satisfaction was transformed such that the intercept reflects low relationship satisfaction ( $-1 \mathrm{SD}$ ). Hence, one standard deviation was added to the grand-mean centered scores. Results revealed two borderline significant effects: participants with high relationship satisfaction ( $+1 \mathrm{SD}$ ) showed an increase in implicit preferences for communal goals in response to the stress priming task, $B=45.62, S E B=23.58, t(45)=1.93, p=.059, d=0.31$. In contrast, participants with low relationship satisfaction ( $-1 \mathrm{SD})$ showed a decrease in preferences for communal goals, $B=-40.85, S E B=24.58, t(45)=-1.73, p=.090, d=0.28$.

\section{Discussion}

Study 1 provides initial support for our hypothesis that the more satisfied people are in their relationship the more they increase their implicit positive attitudes toward communal, helping-related goals in response to their stressed intimate partner who is affected by an external stressor occurring outside the close relationship. Thereby, these individuals prevent the emergence of any motivational conflicts between other-oriented and self-oriented goals. Helping the partner becomes congruent with their current motivational orientation toward communal goals. Potentially incongruent idiosyncratic goals become temporarily less important.

In a second study, we aimed at replicating and extending these findings. First, we wanted to examine whether increased implicit positive attitudes toward communal goals is a self-regulatory mechanism that is particularly prevalent in intimate relationships. Compared to other relationships, like, for instance, friendships, intimate relationships have a much stronger impact on an individual's well-being (Revenson, 1994). Thus, when threatened by external stress, individuals should be particularly motivated to stabilize their intimate relationships. Therefore, we predicted increased implicit positive attitudes toward communal goals to be a specific dyadic mechanism operating to a stronger degree in intimate relationships compared to other social bonds. Again, we hypothesized that this effect should be prevalent in individuals scoring high on relationship satisfaction. To test this assumption, Study 2 used an experimental control group design. Specifically, in Study 2, we compared a partner stress condition with a condition in which participants imagined a fellow student (rather than their intimate partner) suffering from a stressful experience.

A second aim of Study 2 was to examine the behavioral consequences of changes in implicit attitudes toward communal goals. We assumed that a temporarily increased motivational orientation toward communal goals renders supportive behaviors more likely. If this is true, one would expect that the degree of implicit preferences for communal goals would predict inclinations to engage in supportive dyadic coping. To test this hypothesis, Study 2 included a questionnaire at the end of the study in which participants indicated how much they would be inclined to engage in various types of supportive behaviors in the stress scenario presented at the beginning of the study. 
In combination, the predictions for Study 2 constitute a moderated mediation model with stress condition (stressed partner vs. control group) as predictor, relationship satisfaction as moderator, preference for communal goals as mediator, and inclinations to provide support as criterion. See Figure 1 for an illustration of the predicted model.

\section{Study 2}

\section{Method}

\section{Participants}

Eighty-seven students (74 female) from a German university participated in exchange for partial course credit. Two participants were excluded from the analyses due to excessive errors (more than 30\%) in the IAT (average $8.0 \%$ errors). The remaining 85 participants (72 female) had an average age of $M=22.3$ years $(S D=4.2)$ and were all engaged in intimate relationships (average duration 56.6 months, $S D=62.4$ ).

\section{Procedure and materials}

Participants were seated on individual computer workstations and gave informed consent. Participants were randomly assigned to one of two stress conditions (partner stress or control). In order to make the two conditions as parallel as possible, we instructed participants to think of a specific stressor (rather than any stressor) that is experienced by their partner or a fellow student, respectively. Specifically, participants in the partner stress condition received the following instructions: "Please imagine that your partner is suffering from excessive workload." Additionally, participants had to jot down the typical physical and behavioral signs exhibited by their partner when he/she is severely stressed due to high workload. In the control condition, participants did the same for a fellow student. $^{4}$

Afterwards, we assessed implicit attitudes toward communal goals with the same IAT that was used in Study 1. Directly after the IAT, we assessed participants' inclination to provide support in the stress situation they had imagined at the beginning of the study. Thus, participants in the partner stress group indicated whether they are willing to support their partner, whereas participants in the control group indicated their willingness to support their fellow student. We presented 20 selfgenerated items, each describing a supportive behavioral act. Participants had to indicate on a 7point scale the extent to which they would engage in the described behavior. Example items are "I would try to be close to him/her so that he/she does not feel alone with the problems" or "Even if I had lots of things to do on my own, I would immediately do something to help him/her." The internal consistency of the scale was high $(a=.88)$. We computed a composite measure of

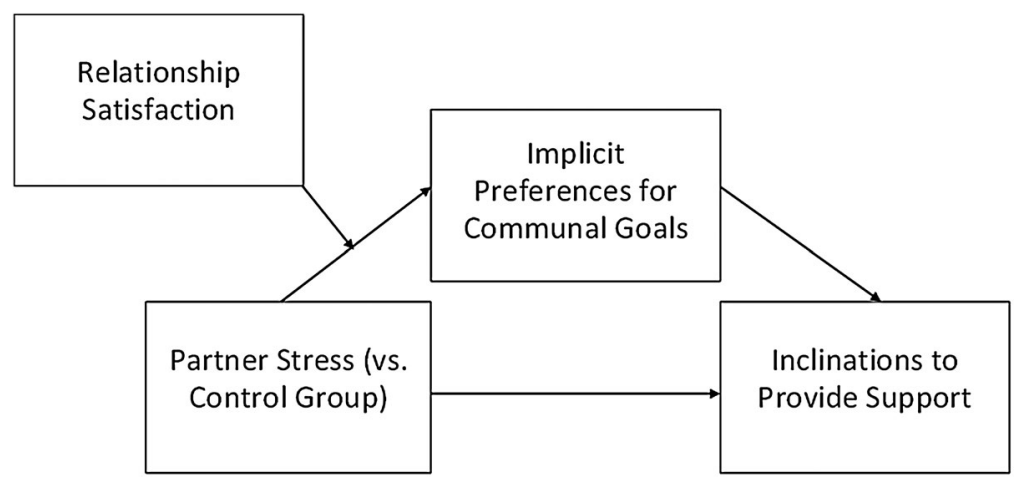

Figure 1. The conceptual moderated mediation model for Study 2. 
inclinations to provide support by calculating the mean over all 20 items. High values indicated a strong inclination to provide support. Finally, participants completed a package of questionnaires which, as in Study 1 , also included the RAS $(M=4.07, S D=0.57, a=.77)$.

\section{Results}

IAT effects indicating implicit preferences for communal goals were calculated according to the same rule as in Study $1 .^{5}$

\section{Analysis strategy}

Our main hypothesis was that participants in the partner stress (vs. control) condition display increased preferences for communal goals and that this effect is more pronounced for participants with high relationship satisfaction. In addition, we expected that the degree of preferences for communal goals would predict inclinations to provide support. Furthermore, we predicted that preferences for communal goals mediate the effect of stress condition on the inclination to provide support and that this indirect effect should be especially pronounced for participants with high relationship satisfaction. In combination, these predictions constitute a moderated mediation model. To test this model, we used the analysis tool PROCESS (Model 7; Hayes, 2012) which combines multiple regression and bootstrapping methods. This analysis included the regression of implicit preferences for communal goals on experimental stress condition ( $1=$ partner stress; $0=$ control group), relationship satisfaction (centered), and the interaction of both predictors. Moreover, inclination to provide support was regressed on implicit preferences for communal goals plus stress condition. Mediation of the effect of stress condition on inclinations to provide support via preferences for communal goals was tested with bootstrapping applying 10,000 resamples.

\section{Implicit attitudes toward communal goals}

Results revealed a main effect of experimental condition, $B=53.23$, SE $B=24.74, t(81)=2.15, p=.034$, $d=0.42$, indicating that implicit preference for communal goals were higher in the partner stress condition $(M=178, S D=138)$ compared to the control group $(M=128, S D=99)$. This effect was further qualified by an interaction of stress condition $\times$ relationship satisfaction, $B=111.53, S E B=43.80, t(81)$ $=2.55, p=.013$. In line with our hypothesis, partner stress (vs. stress of a student colleague) increased implicit positive attitudes toward communal goals in participants with high relationship satisfaction (i.e., one standard deviation above the mean), $B=116.95, S E B=35.12, t(81)=3.33, p=.001$, but not in participants with low relationship satisfaction (i.e., one standard deviation below the mean), $B=-10.47, S E B=35.25, t<1$. Figure 2 depicts these results. The main effect of relationship satisfaction was not significantly different from zero $(t<1)$.

\section{Inclinations to provide support}

Increased implicit preferences for communal goals should be linked to stronger inclinations to provide support. Consistent with that assumption, implicit attitudes toward communal goals predicted inclinations to provide support, $B=0.001, S E B=0.0006, t(81)=2.07, p=.041$, beyond and above a main effect of stress condition, $B=0.42, S E B=0.16, t(81)=2.72, p=.008, d=0.69$. The main effect of stress condition reflected that support provision was higher in the partner stress condition $(M=4.84, S D=0.64)$ compared to the control group $(M=4.35, S D=0.77)$.

To determine whether stress condition had an effect on inclinations to provide support via implicit attitudes toward communal goals, we viewed the bootstrap 95\% confidence intervals separately for high, moderate and low values of relationship satisfaction (see Preacher, Rucker, \& Hayes, 2007). The confidence interval for high $[0.023,0.37]$ and moderate $[0.009,0.18]$ values of relationship satisfaction did not include zero, indicating that these indirect effects were significantly different from zero at $a=.05$ (point estimate for indirect effects: 0.16 [SE $=0.08$ ] for high and 0.07 [SE $=0.04$ ] for moderate levels of relationship satisfaction). In other words, partner stress and inclinations to engage in dyadic 


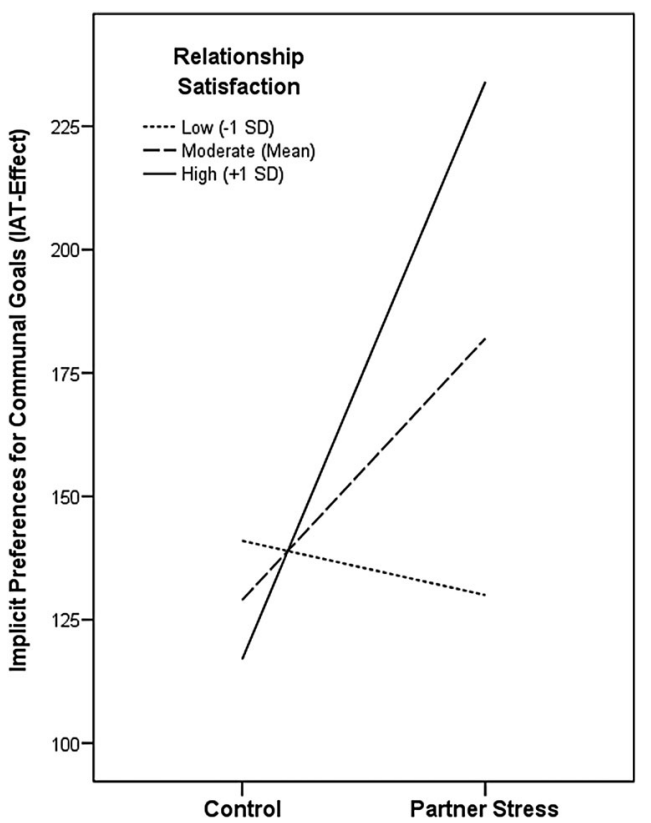

Figure 2. Effects of stress condition on implicit preferences for communal goals: moderating effects of relationship satisfaction (Study 2).

coping were indirectly linked, mediated via implicit positive attitudes toward communal goals. This was not the case for low values of relationship satisfaction in which the confidence interval $[-0.15$, $0.045]$ contained zero (point estimates for indirect effect: -0.01 [SE $=0.05]$ ).

\section{Discussion}

Study 2 substantially extended the findings of Study 1 . In a between-subjects control group design, we found stronger implicit preferences for communal goals in a condition of partner stress compared to a control group in which a fellow student suffered from stress. This effect was more pronounced for participants with high relationship satisfaction. The first novel finding relates to the main effect of stress condition. This effect indicates that the increased motivational orientation toward communal goals is a couple-specific response to a stressed intimate partner that is absent (or reduced) in response to a stressed friend. The second novel finding was that implicit attitudes toward communal goals predicted inclinations to provide support in the stress-inducing situation. Study 2's findings thus illuminate the link between partner stress and supportive dyadic coping. Specifically, for participants with moderate or high levels of relationship satisfaction, increased supportive behavior in response to a stressed intimate partner is partially mediated via increased implicit positive attitudes toward communal goals.

\section{General discussion}

The present research aimed at examining the implicit self-regulatory mechanisms that underlie dyadic support processes in intimate couples depending on relationship satisfaction. The studies were theoretically grounded in the STM (Bodenmann, 1995, 2005), a widely used model of dyadic coping (Falconier et al., 2016) and the framework of implicit self-regulation (e.g., Fishbach et al., 2010; Koranyi, 2012; Koranyi et al., 2013; Koranyi \& Meissner, 2015; Koranyi \& Rothermund, 2012a, 2012b, 2012c; Shah et al., 2002). Results of the two reported studies support the assumption that 
when confronted with a stressed partner, participants change implicit positive attitudes toward communal goals. Correlational Study 1 showed that this effect is positively related to relationship satisfaction. The more partners are satisfied with their relationship the more their positive attitude toward communal goals increases after reflecting on a stressed partner. This result was replicated in Study 2 with a between-subjects control group experiment, where we found that partner stress (compared to stress of a friend) increased implicit positive attitudes toward communal goals at moderate and high levels of relationship satisfaction. In addition, Study 2 revealed that implicit preferences for communal goals predicted stronger inclinations to engage in supportive dyadic coping. In fact, for participants with at least moderate levels of relationship satisfaction, partner stress and inclinations to provide support were indirectly linked via implicit preferences for communal goals.

It has long been established in psychological stress research that support provided by intimate relationship partners is of primary significance and exceeds by far support from other sources (e.g., Bodenmann, 1995, 2005; Coyne \& DeLongis, 1986; Revenson, 1994). Although the role of dyadic coping for couple's functioning (satisfaction and stability) has been well documented (Falconier et al., 2015, 2016), the underlying motivational regulation processes of support provision in intimate dyads have received far less attention. Specifically, only little is known about how partners deal with potential motivational conflicts between helping goals and personal, idiosyncratic goals in situations of high partner stress. What has already been shown is that partners manage to provide supportive dyadic coping by recruiting counteracting beliefs about their partners (e.g., "he/she is so valuable" or "he/she provides also support when I'm stressed"; Murray et al., 2003, 2006, 2009). The present research extends these findings by showing that individuals who feel satisfied with their close relationship engage in a spontaneous self-regulation process, by which perceptions of one's stressed partner trigger increased implicit positive attitudes toward communal, helpingrelated goals. In turn, this preference shift in motivational orientation supports execution of supportive behaviors. Our results are in line with the finding that individuals scoring high on relationship satisfaction indicate that they experience the act of helping their partner itself as positive (Feeney $\&$ Collins, 2003)

The present research treated relationship satisfaction as a predictor, which determines who will react to partner stress with enhanced implicit orientation toward communal goals and in turn engage in supportive behavior. This perspective is consistent with previous research suggesting that there is a reciprocal relationship between dyadic coping and relationship satisfaction (Bodenmann et al., 2006; lida et al., 2008). Typically, partners with already high relationship satisfaction are prone to engage in dyadic coping, which as a consequence strengthens their relationship (Bodenmann, 2005; Cutrona, 1996). This view implies that the erosion of either relationship satisfaction or dyadic coping can set up a vicious downward spiral in relationship quality. In line with this assumption, Study 1 showed that for participants with low relationship satisfaction partner stress reduced implicit attitude toward communal goals, which itself may radiate back to reduce commitment to the relationship. However, in the present studies, relationship satisfaction was only measured. It is possible that the relationship observed between relationship satisfaction and a change in implicit attitudes toward communal goals is caused by a third variable that was not considered (e.g., empathy or self-regulation capacity). In order to make a causal inference, future research should find ways to manipulate relationship satisfaction experimentally, for example, by letting participants imagine either positive or negative experiences with their partner (Job, Bernecker, \& Dweck, 2012) prior to the partner stress induction.

Our results might help to better understand recent findings in intimate relationship research. Neff and Broady (2011) found that spouses who experienced moderate stress during their early month of marriage and who had good relationship resources (i.e., support behaviors) showed better marital adjustment after transition to parenthood compared to spouses who had good resources but less prior experience with stress. Our findings suggest that those who experienced stress during early phases of marriage engaged in dyadic coping caused by a change in implicit communal orientation. This could have strengthened the association between partner stress and communal goal orientation 
in a still relatively relaxed time. This established link might then serve as a coping resource for dealing with later stress during the relationship, such as, for instance, stress related to parenthood.

\section{Limitations, future research, and intervention}

It should be noted that a limitation of the current study is that we only assessed inclinations to provide support rather than actual support behavior. Given that implicit preferences and motives have been shown to be good predictors of spontaneous behavior (e.g., Ellwart, Rinck, \& Becker, 2006; Rudolph, Schröder-Abé, Riketta, \& Schütz, 2010; Steffens \& König, 2006), we would assume that implicit communal orientations should predict behavioral measures of supportive coping at least as well as behavioral inclinations. However, this remains an open question, which should be addressed by future research (e.g., by assessing observational data).

A second limitation relates to the scope of our findings. In experimental Study 2, we compared implicit preferences for communal goals between two stress conditions in which either the partner (experimental condition) or a fellow student (control group) suffered from excessive work load. We chose the fellow student condition as control group to show that increased preferences for communal goals is a coping response that enables (at least some) couples to buffer external stress that could easily spill over to the partner. Such spillover is more likely to occur in couples, given that interdependence and closeness are typically stronger in couples compared to other social bonds (e.g., friends or colleagues, Bodenmann, 1995, 2005; Coyne \& DeLongis, 1986; Revenson, 1994). Therefore, we assumed that the coping response would be more pronounced in couples when compared with other social relationships. Thus, the present studies were designed to test this couplespecificity hypothesis. What they do not answer is the question about how stress-specific the increase in communal goal orientation is. In other words, the current studies do not rule out the possibility that implicit preferences for communal goals increase in response to any (i.e., also non-stress) situation in which the partner is salient. However, for the following reason we do not think that this is very likely. Results of Study 2 show that implicit preferences for communal goals predict inclinations to provide support. This finding suggests that the examined mechanism underlies supportive dyadic coping responses (e.g., being empathetic and supportive). These types of behavior are adaptive in regulating the partner's stress response but are ineffective in many other relationship situations. For example, they would not be functional when partners conjointly work toward clearly defined tasks like preparing dinner or going on a bike ride. In these situations, we would predict that despite the presence of the partner individuals should evaluate agentic goals as least as positive as communal goals in order to support task-oriented action-regulation. Nevertheless, this question deserves further research. It would be highly interesting to compare implicit preferences for communal goals between two conditions with high partner salience but different levels of partner stress (high vs. low).

Our findings open up for various lines of future research. First, the present research focused on the regulatory responses within individuals whose intimate partners suffer from emotional disturbances and daily stress. It would be a highly interesting line for future research to examine on a dyadic level the effectiveness of dyadic coping that is underpinned with such self-regulatory adjustments of communal goal orientations. Weinstein and Ryan (2010) found that pro-social behavior is more effective if the support provider experiences the execution of helping behavior itself as positive and driven by internal forces rather than external pressure (see also Impett, Le, Kogan, Oveis, \& Keltner, 2014). In line with that, we would expect a decreased impact of partner A's external stress on his/her well-being when partner $B$ displays a strong increase in communal goal orientations in response to A's stress signals.

Second, future research should also focus on boundary conditions. It seems likely that high levels of own stress or an important ongoing task inhibit the activation of regulatory responses that operate in favor of communal other-focused orientations (Feeney \& Collins, 2003), as also described in STM (Bodenmann, 1995). In addition, the regulatory response should be influenced by the specific signs that are communicated by the stressed partner. In many cases, individuals communicate 
their stress on a matter-of-fact level and focus on the situation characteristics (e.g., "The project has to be presented to the supervisor tomorrow.") rather than their physical or emotional experience ("I'm afraid of being negatively evaluated."). Given that individuals typically respond stronger the more their partner is emotionally touched (Wagemans \& IJzerman, 2014), we would expect the latter type of communication to be a much better cue for activating communal-related self-regulatory responses. In addition, in some cases of extreme partner stress, individuals might initially increase positive attitudes toward communal goals but refrain from executing support behavior anyway because they reflect that the stress level of their partner exceeds their own resources. This may be particularly the case in chronic strain situations such as a partner's severe illness or handicap. Thus, our findings are not generalizable to external chronic and major stressors (Randall \& Bodenmann, 2009).

Finally, it is likely that there are dispositional variables that moderate the effect of partner stress on implicit communal orientations. For instance, individuals with an avoidant attachment style provide less support when their relationship partner is stressed (Simpson, Rholes, Oriña, \& Grich, 2002). This effect might be explained by attachment-related differences in how implicit positive attitudes toward communion are activated in response to a stressed partner. Furthermore, one could consider gender as another possible moderator. Generally, women score higher on communion-related traits than men (for a meta-analysis, see Feingold, 1994). However, this does not necessarily imply that women also show stronger temporal increase in preferences for communal goals in response to partner stress. Additionally, within the context of romantic relationships men tend to engage in communal behavior as often as women (Suh, Moskowitz, Fournier, \& Zuroff, 2004). Unfortunately, our samples consisted mostly of females (Study 1: 94\%; Study 2: 85\%), which precludes examining any moderating influence of gender. Thus, further research on the dynamics of implicit preferences for communal goals in couples should ensure a more equal distribution of male and female participants.

On the basis of our findings one might speculate how intervention programs might help unsatisfied couples to overcome the vicious circle of reduced mutual support and relationship dissatisfaction. The current studies suggest that individuals with low relationship satisfaction do not show a spontaneous preference for other-oriented goals when their partner is stressed. One may wonder whether setting explicit goals to support the partner could help increase communal goal orientation in these people as a response to partner stress. For example, couples might benefit from a training in which they learn strategically to respond supportively (see Couples Coping Enhancement Training; Bodenmann \& Shantinath, 2004). Theories on the automatization of behavior suggest that if support is consistently activated in response to a stressed partner, the helping goal might become automatically activated eventually (e.g., Bargh \& Barndollar, 1996). However, trying to provoke support through this sort of controlled regulation might bear the risk of inauthentic behavior. People are relatively good in detecting when a romantic partner's favor goes along with suppression of his or her own interests and emotions (Impett et al., 2014; see also Weinstein \& Ryan, 2010). Partner inauthenticity in turn significantly reduces personal well-being and relationship satisfaction (Impett et al., 2014). Thus, any intervention that focuses on controlled regulation of support provision has to ensure that both partners are committed toward the intervention program and the goal of maintaining their relationships.

\section{Conclusion}

In summary, the present research showed that intimate partners who feel satisfied with their close relationship increase implicit positive attitudes toward communal goals in situations of high partner stress, which in turn predicts stronger inclinations to provide supportive coping. By engaging in this self-regulation process, individuals prevent the experience of motivational conflicts between partner-directed and self-directed goals and help to counteract potential negative external influences on couple functioning. 


\section{Notes}

1. It is worthy to note that the type of stress that is addressed in the present research is stress that originates outside the relationship. When the relationship itself becomes the source of one's partner's stress, we would expect selfprotection goals (e.g., Murray et al., 2003) and avoidance motivation (Cavallo, Fritzsimons, \& Holmes, 2010) to be activated rather than supportive dyadic coping.

2. In both studies, participants indicated their relationship status at the beginning of the experiment. Students who were not engaged in an intimate relationship participated in a different study.

3. The first four trials of the combined blocks were treated as practice trials and did not enter into the analyses. RTs that were more than three interquartile ranges above the third quartile of an individual's RT distribution (i.e., farout values, Tukey, 1977; 4.7\% baseline assessment, and 5.5\% post-assessment) were discarded. Visual inspection revealed $350 \mathrm{~ms}$ as a lower threshold of the RT distribution. RTs below this threshold were eliminated as well $(<0.1 \%$ for both IATs). Erroneous trials were also excluded from analyses ( $2.4 \%$ baseline assessment and $3.0 \%$ post-assessment).

4. For reasons beyond the scope of the present research, we also assessed implicit motives with a picture story exercise (Schultheiss \& Brunstein, 2001) immediately prior and after the stress manipulation. In both testing sessions, participants were asked to write three imaginative stories based on picture cues (duration of each session: approximately 8-12 $\mathrm{min}$ ).

5. As in Study 1, trials with erroneous responses (4.3\%) and outlier values (2.6\%) were discarded from the analyses.

\section{Disclosure statement}

No potential conflict of interest was reported by the authors.

\section{Funding}

This work was supported by the Deutsche Forschungsgemeinschaft [grant number KO 4662/2-1].

\section{References}

Badr, H., Carmack, C. L., Kashy, D. A., Cristofanilli, M., \& Revenson, T. A. (2010). Dyadic coping in metastatic breast cancer. Health Psychology, 29, 169-180. doi:10.1037/A0018165

Bargh, J. A., \& Barndollar, K. (1996). Automaticity in action: The unconscious as repository of chronic goals and motives. In P. M. Gollwitzer \& J. A. Bargh (Eds.), The psychology of action (pp. 457-471). New York, NY: Guilford.

Bodenmann, G. (1995). A systemic-transactional conceptualization of stress and coping in couples. Swiss Journal of Psychology, 54, 34-49.

Bodenmann, G. (2005). Dyadic coping and its significance for marital functioning. In T. A. Revenson \& K. Kayser (Eds.), Couples coping with stress: Emerging perspectives on dyadic coping (pp. 33-49). Washington, DC: American Psychological Association.

Bodenmann, G., Meuwly, N., \& Kayser, K. (2011). Two conceptualizations of dyadic coping and their potential for predicting relationship quality and individual well-being: A comparison. European Psychologist, 16, 255-266. doi:10.1027/ 1016-9040/a000068

Bodenmann, G., Pihet, S., \& Kayser, K. (2006). The relationship between dyadic coping and marital quality: A 2-year longitudinal study. Journal of Family Psychology, 20, 485-493. doi:10.1037/0893-3200.20.3.485

Bodenmann, G., \& Shantinath, S. D. (2004). The Couples Coping Enhancement Training (CCET): A new approach to prevention of marital distress based upon stress and coping. Family Relations, 53, 477-484. doi:10.1111/j.0197-6664.2004. 00056.x

Cavallo, J. V., Fitzsimons, G. M., \& Holmes, J. G. (2010). When self-protection overreaches: Relationship-specific threat activates domain-general avoidance motivation. Journal of Experimental Social Psychology, 46, 1-8. doi:10.1016/j.jesp. 2009.07.007

Coyne, J. C., \& DeLongis, A. (1986). Going beyond social support: The role of social relationships in adaptation. Journal of Consulting and Clinical Psychology, 54, 454-460. doi:10.1037/0022-006x.54.4.454

Cutrona, C. E. (1996). Social support in couples. Marriage as a resource in times of stress. Thousand Oaks, CA: Sage.

Derrick, J. L., Leonard, K. E., \& Homish, G. G. (2012). Dependence regulation in newlywed couples: A prospective examination. Personal Relationships, 19, 644-662. doi:10.1111/j.1475-6811.2011.01384.x

Ellwart, T., Rinck, M., \& Becker, E. S. (2006). From fear to love: Individual differences in implicit spider associations. Emotion, 6, 18-27. doi:10.1037/1528-3542.6.1.18

Falconier, M. K., Jackson, J. B., Hilpert, P., \& Bodenmann, G. (2015). Dyadic coping and relationship satisfaction: A metaanalysis. Clinical Psychology Review, 42, 28-46. doi:10.1016/j.cpr.2015.07.002 
Falconier, M. K., Randall, A. K., \& Bodenmann, G. (Eds.). (2016). Couples coping with stress: A cross-cultural perspective. New York, NY: Routledge.

Feeney, B. C., \& Collins, N. L. (2003). Motivations for caregiving in adult intimate relationships: Influences on caregiving behavior and relationship functioning. Personality and Social Psychology Bulletin, 29, 950-968. doi:10.1177/ 0146167203252807

Feingold, A. (1994). Gender differences in personality: A meta-analysis. Psychological Bulletin, 116, 429-456. doi:10.1037/ 0033-2909.116.3.429

Fishbach, A., Zhang, Y., \& Trope, Y. (2010). Counteractive evaluation: Asymmetric shifts in the implicit value of conflicting motivations. Journal of Experimental Social Psychology, 46, 29-38. doi:10.1016/j.jesp.2009.09.008

Greenwald, A. G., McGhee, D. E., \& Schwartz, J. L. K. (1998). Measuring individual differences in implicit cognition: The implicit association test. Journal of Personality and Social Psychology, 74, 1464-1480. doi:10.1037/0022-3514.74.6.1464

Hayes, A. F. (2012). PROCESS: A versatile computational tool for observed variable mediation, moderation, and conditional process modeling [White paper]. Retrieved from http://www.afhayes.com/public/process2012.pdf

Hendrick, S. S. (1988). A generic measure of relationship satisfaction. Journal of Marriage \& the Family, 50, 93-98. doi:10. 2307/352430

Herzberg, P. Y. (2013). Coping in relationships: The interplay between individual and dyadic coping and their effects on relationship satisfaction. Anxiety Stress and Coping, 26, 136-153. doi:10.1080/10615806.2012.655726

Holoien, D. S., \& Fiske, S. T. (2013). Downplaying positive impressions: Compensation between warmth and competence in impression management. Journal of Experimental Social Psychology, 49, 33-41. doi:10.1016/j.jesp.2012.09.001

lida, M., Seidman, G., Shrout, P. E., Fujita, K., \& Bolger, N. (2008). Modeling support provision in intimate relationships. Journal of Personality and Social Psychology, 94, 460-478. doi:10.1037/0022-3514.94.3.460

Impett, E. A., Le, B. M., Kogan, A., Oveis, C., \& Keltner, D. (2014). When you think your partner is holding back: The costs of perceived partner suppression during relationship sacrifice. Social Psychological and Personality Science, 5, 542-549. doi:10.1177/1948550613514455

Job, V., Bernecker, K., \& Dweck, C. S. (2012). Are implicit motives the need to feel certain affect? Motive-affect congruence predicts relationship satisfaction. Personality and Social Psychology Bulletin, 38, 1552-1565. doi:10.1177/ 0146167212454920

Kelley, H. H., \& Thibaut, J. W. (1978). Interpersonal relations: A theory of interdependence. New York, NY: Wiley.

Koranyi, N. (2012). Automatic self-regulation in committed relationships: Mechanisms underlying attainment of initiation and stabilization goals (Unpublished doctoral dissertation). University of Jena, Jena.

Koranyi, N., Gast, A., \& Rothermund, K. (2013). "Although quite nice, I was somehow not attracted by that person": Attitudes towards romantically committed opposite-sex others are immune to positive evaluative conditioning. Social Psychological and Personality Science, 4, 403-410. doi:10.1177/1948550612467037

Koranyi, N., \& Meissner, F. (2015). Handing over the reins: Neutralizing negative attitudes toward dependence in response to reciprocal romantic liking. Social Psychological and Personality Science, 6, 685-691. doi:10.1177/1948550615580169

Koranyi, N., \& Rothermund, K. (2012a). Automatic coping mechanisms in committed relationships: Increased interpersonal trust as a response to stress. Journal of Experimental Social Psychology, 48, 180-185. doi:10.1016/j.jesp.2011.06.009

Koranyi, N., \& Rothermund, K. (2012b). Interactive self-regulation during mate searching: Reciprocal romantic interest increases attention allocation to opposite-sex others. Journal of Psychology/Zeitschrift für Psychologie, 220, $194-199$. doi:10.1027/2151-2604/a000113

Koranyi, N., \& Rothermund, K. (2012c). When the grass on the other side of the fence doesn't matter: Reciprocal romantic interest neutralizes attentional bias towards attractive alternatives. Journal of Experimental Social Psychology, 48, 186191. doi:10.1016/j.jesp.2011.06.012

Maner, J. K., Gailliot, M. T., \& Miller, S. L. (2009). The implicit cognition of relationship maintenance: Inattention to attractive alternatives. Journal of Experimental Social Psychology, 45, 174-179. doi:10.1016/j.jesp.2008.08.002

Meissner, F., \& Rothermund, K. (2013). Estimating the contributions of associations and recoding in the Implicit Association Test: The ReAL model for the IAT. Journal of Personality and Social Psychology, 104, 45-69. doi:10.1037/ a0030734

Murray, S. L., Bellavia, G. M., Rose, P., \& Griffin, D. W. (2003). Once hurt, twice hurtful: How perceived regard regulates daily marital interactions. Journal of Personality and Social Psychology, 84, 126-147. doi:10.1037/0022-3514.84.1.126

Murray, S. L., Holmes, J. G., Aloni, M., Pinkus, R. T., Derrick, J. L., \& Leder, S. (2009). Commitment insurance: Compensating for the autonomy costs of interdependence in close relationships. Journal of Personality and Social Psychology, 97, 256278. doi:10.1037/A0014562

Murray, S. L., Holmes, J. G., \& Collins, N. L. (2006). Optimizing assurance: The risk regulation system in relationships. Psychological Bulletin, 132, 641-666. doi:10.1037/0033-2909.132.5.641

Myrseth, K. O. R., Fishbach, A., \& Trope, Y. (2009). Counteractive self-control: When making temptation available makes temptation less tempting. Psychological Science, 20, 159-163. doi:10.1111/j.1467-9280.2009.02268.x

Neff, L. A., \& Broady, E. F. (2011). Stress resilience in early marriage: Can practice make perfect? Journal of Personality and Social Psychology, 101, 1050-1067. doi:10.1037/A0023809

O'Hagen, S., Johnson, A., Lardi, G., \& Keenan, J. P. (2003). The effect of relationship status on perceived attractiveness. Social Behavior \& Personality, 31, 291-299. doi:10.2224/sbp.2003.31.3.291 
Papp, L. M., \& Witt, N. L. (2010). Romantic partners' individual coping strategies and dyadic coping: Implications for relationship functioning. Journal of Family Psychology, 24, 551-559. doi:10.1037/a0020836

Preacher, K. J., Rucker, D. D., \& Hayes, A. F. (2007). Addressing moderated mediation hypotheses: Theory, methods, and prescriptions. Multivariate Behavioral Research, 42, 185-227. doi:10.1080/00273170701341316

Randall, A. K., \& Bodenmann, G. (2009). The role of stress on close relationships and marital satisfaction. Clinical Psychology Review, 29, 105-115. doi:10.1016/j.cpr.2008.10.004

Revenson, T. A. (1994). Social support and marital coping with chronic illness. Annals of Behavioral Medicine, 16, $122-130$.

Rudolph, A., Schröder-Abé, M., Riketta, M., \& Schütz, A. (2010). Easier when done than said! Implicit self-esteem predicts observed or spontaneous behavior, but not self-reported or controlled behavior. Journal of Psychology/Zeitschrift für Psychologie, 218, 12-19. doi:10.1027/0044-3409/A000003

Sander, J., \& Böcker, S. (1993). Die Deutsche Form der Relationship Assessment Scale (RAS): Eine kurze Skala zur Messung der Zufriedenheit in einer Partnerschaft [The German version of the relationship assessment scale (RAS): A short scale for measuring satisfaction in a dyadic relationship]. Diagnostica, 39, 55-62.

Schultheiss, O. C., \& Brunstein, J. C. (2001). Assessment of implicit motives with a research version of the TAT: Picture profiles, gender differences, and relations to other personality measures. Journal of Personality Assessment, 77, 71-86.

Shah, J. Y., Friedman, R., \& Kruglanski, A. W. (2002). Forgetting all else: On the antecedents and consequences of goal shielding. Journal of Personality and Social Psychology, 83, 1261-1280. doi:10.1037/0022-3514.83.6.1261

Simpson, J. A., Rholes, W. S., Oriña, M. M., \& Grich, J. (2002). Working models of attachment, support giving, and support seeking in a stressful situation. Personality and Social Psychology Bulletin, 28, 598-608. doi:10.1177/0146167202288004

Steffens, M. C., \& König, S. S. (2006). Predicting spontaneous big five behavior with implicit association tests. European Journal of Psychological Assessment, 22, 13-20. doi:10.1027/1015-5759.22.1.13

Suh, E. J., Moskowitz, D. S., Fournier, M. A., \& Zuroff, D. C. (2004). Gender and relationships: Influences on agentic and communal behaviors. Personal Relationships, 11, 41-60. doi:10.1111/j.1475-6811.2004.00070.x

Tukey, J. W. (1977). Exploratory data analysis. Reading, MA: Addision-Wesley.

Wagemans, F. M. A., \& IJzerman, H. (2014, February). Social thermoregulation in close relationships. Poster presented at the annual meeting of the Society for Personality and Social Psychology, Austin, TX, USA.

Weinstein, N., \& Ryan, R. M. (2010). When helping helps: Autonomous motivation for prosocial behavior and its influence on well-being for the helper and recipient. Journal of Personality and Social Psychology, 98, 222-244. doi:10.1037/ a0016984 